\section{Genetic determinants of the Ponzo illusion*}

\author{
ADAM P. MATHENY, JR. \\ Health Sciences Center \\ University of Louisville School of Medicine, Louisville, Ky. 40202
}

The Ponzo illusion was studied in 36 pairs of same-sex twins ranging in age from 9 to 11 years. Serological tests indicated that there were 21 identical and 15 fraternal twin pairs. Intrapair differences in the magnitude of the illusion were significantly less for identical pairs, indicating an heredity component in the illusion.

In spite of numerous studies on the Ponzo illusion, little is known about the basis or causes of the illusion (Leibowitz \& Judisch, 1967; Leibowitz \& Gwozdecki, 1967). While there is evidence for some influence of heredity on the Mueller-Lyer illusion (Smith, 1949), similar evidence has not been presented for the role of heredity on the Ponzo illusion. To investigate this possibility, we have applied the classical twin method to a study of children's perception of the illusion.

The Ponzo illusion is thought to belong to a general class of illusory phenomena, sometimes called Type II or secondary illusion, which increase with age (Parrish et al, 1968; Piaget, 1969). The Ponzo figure, shown in Fig. 1 (inset), typically elicits an illusion that two equal vertical lines appear to be unequal in length. Previous research indicates that the magnitude of the illusion systematically increases throughout childhood, levels off in adulthood, and decreases in old age (Leibowitz \& Judisch, 1967). This is in contrast with the systematic decrease of the magnitude of the Type I or primary illusions with age, as exemplified by the Mueller-Lyer illusion (Piaget, 1969).

SUBJECTS AND PROCEDURES

From a longitudinal study ${ }^{1}$ of twin children, 36 pairs of same-sex twins (17 male, 19 female), ranging in age from 9 to 11 years, were presented with a series of 14 cards bearing the Ponzo figures. In the series, the vertical line nearest the apex of the figure varied in length from 0.5 to 1.3 in., in 0.06 -in. steps. The other vertical line was constant in length at 1 in. As in the method of constant

*The Lousiville Twin Study currently includes over 230 pairs of twins, ranging in age from birth through 11 years, and it focuses on the major aspects of psychological development. The research program is supported by PHS Research Grant HD 03217 from the National Institute of Child Health and Human Development, with R. S. Wilson as principal investigator. E. Harpring, M. Moseson, and $J$. Parker assisted in the data collection for this study. stimuli, the series was randomly presented, 1 card at a time, to the child. The cards were placed flat on a table at a viewing distance of about $2 \mathrm{ft}$. Each card was arranged so that the apex of the Ponzo figure was always to the child's left and the vertical lines were perpendicular to the edge of the table. The task demanded that the child indicate whether the vertical line nearest the apex was longer or shorter than the other vertical line. To ensure that the child understood the task, 2 cards with obvious differences between the vertical lines were given to the child, and, if necessary, the child was shown that one line was longer than the other. Different examiners gave the series to each member of the twin pair, and neither examiner was aware of the method for determining the magnitude of the illusion. A third person

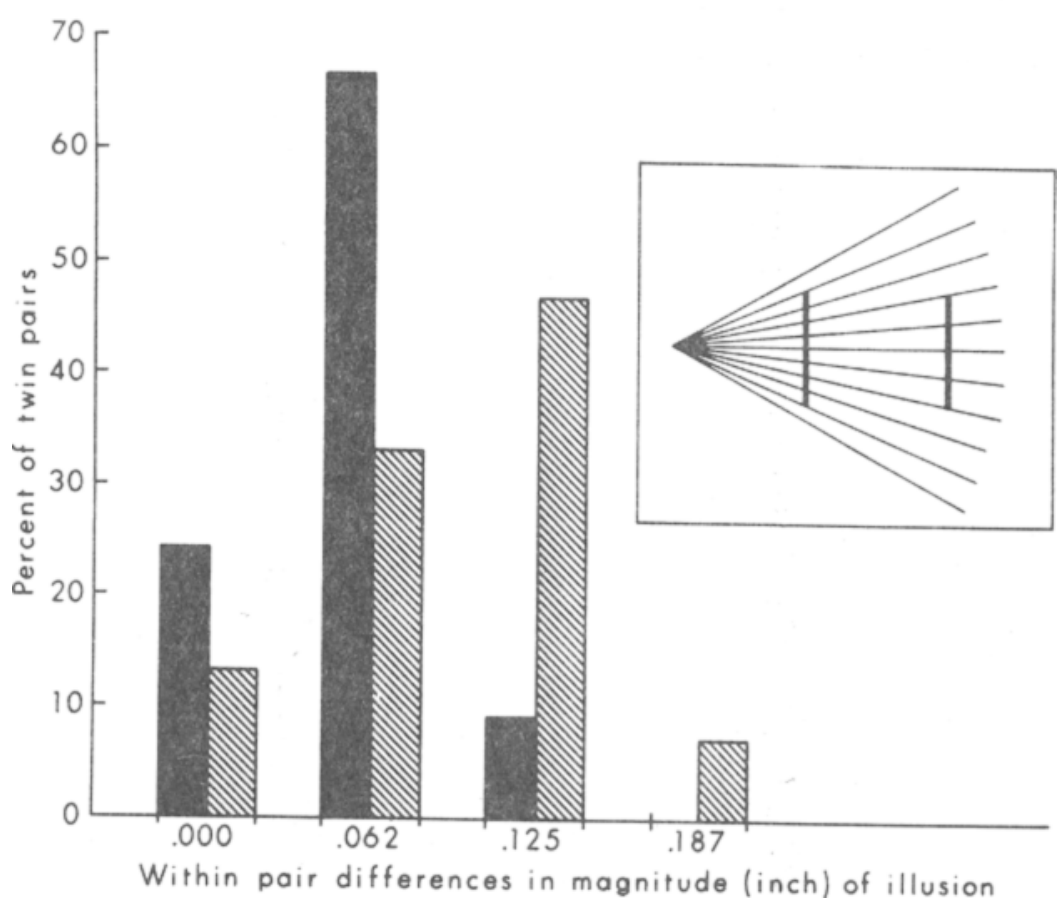

Fig. 1. Typical Ponzo figure (inset). The solid bars in the graph represent identical twins; the hatched bars represent fraternal twins. illusion. The distributions overlap but calculated the magnitude of the illusion by interpolating the point at which the vertical lines were seen as equal in length and subtracting that value from the 1 -in. standard.

Zygosity of the twins had been determine;several years prior to their being given the Ponzo figures. The determination was based on concordance or nonconcordance on 22 or more blood-group factors (Race \& Sanger, 1968; Wilson, 1970). Any discrepancy on any of the antisera tests classified the pair as fraternal. There were 21 identical and 15 fraternal twin pairs.

\section{RESULTS}

An inspection of the distribution of the magnitudes of the illusion indicated that the distribution was leptokurtic. As Stafford (1969) has pointed out, when small sample sizes with nonnormal distributions are found, twin data can be analyzed appropriately by nonparametric statistics. Figure 1 shows the distribution of the percentage of identical and fraternal twin pairs, demonstrating intrapair differences in the magnitude (inch) of the Ponzo are clearly distinct. A one-tailed test using the Mann-Whitney U nonparametric test (Siegel, 1956) indicated that the intrapair differences in the magnitude of the illusion were significantly less $(z=2.26, p=.01)$ for the identical twins. 


\section{DISCUSSION}

Although estimates of heritability were not calculated from these data, it is apparent that heredity, as well as age, contributes to the degree of susceptibility to the Ponzo illusion. The influence of heredity on visual geometric-optical illusions has received little attention, except for the Mueller-Lyer illusion (Smith, 1949); however, hereditary components have been shown for a variety of other perceptual tasks, some of which depend on visual experiences not precisely matching reality (Eysenck \& Prell, 1951; Vandenberg, 1962).

In addition to the demonstration that heredity is a basic determinant of susceptibility to the Ponzo illusion within a given age span, we think that heredity may be a basic determinant of longitudinal changes in the illusion. In this case, the general increase in the magnitude of the illusion would depend on hereditary components governing the development of perception. Such genetic control has already been found for the rate of development of skeletal maturity such as the ossification of round bones, height (Vandenberg \& Falkner, 1966), and the motor development of infant twins. ${ }^{1}$
Large differences in the magnitude of the illusion for two pairs of identical twins deserve special attention. Both pairs, one male and one female, had intrapair differences of $0.125 \mathrm{in}$. in the magnitude of the illusion. Pollack (1969) has hypothesized that the magnitude of Type II illusions-the class to which the Ponzo belongs-is a function of the development of temporal sequencing such as repeating a number series. In support of this hypothesis, within both twin pairs, the twin demonstrating the greater susceptibility to the illusion was the one with a higher scaled score on a digit span subtest of an intelligence test. This observation suggests that, despite the Ponzo illusion being considered a result of perceptual processes, there are cognitive aspects to the development of the illusion.

\section{REFERENCES}

EYSENCK, H. J., \& PRELL, D. B. The inheritance of neuroticism, an experimental study. Journal of Mental Science. 1951, 97, 411-465.

LEIBOWITZ, H. W., \& GWOZDECKI, J. The magnitude of the Poggendorff illusion as a function of age. Child Development, 1967, 38, 573-580.
LEIBOWITZ, H. W., \& JUDISCH, J, M. The relation between age and the magnitude of the Ponzo illusion. American Journal of Psychology, 1967, 80, 105-110.

PARRISH, M., LUNDY, R. M. \& LEIBOWITZ, H. W. Hypnotic age-regression and magnitudes of the Ponzo and Poggendorff illusions. Science, $1968,159,1375-1376$.

PIAGET, J. The mechanisms of perception. New York: Basic Books, 1969.

POLLACK, R. H. Some implications of ontogenetic changes in perception. In $D$. Elkind and J. H. Flavell (Eds.), Studies in cognitive development. New York: Oxford University Press, 1969.

RACE, R. R., \& SANGER, R. Blood groups in man. Philadelphia: Davis, 1968.

SIEGEL, S. Non-parametric statistics. New York: McGraw-Hill, 1956.

SMITH, G. Psychological studies in twin differences. Lund, Sweden: Gleerup, 1949.

STAFFORD, R. E. The case for nonparametric statistics in the analy sis of twin data. Human Heredity, 1969, 19. 601-608.

VANDENBERG, S. G. The hereditary abilities study: Hereditary components in a psychological test battery. American Journal of Human Genetics, 1962, 14, 220-237.

VANDENBERG, S. G., \& FALKNER,F, Hereditary factors in human growth. Human Biology, 1966, 37, 357-365.

wiLSON, R. S. Bloodtyping and twin zygosity. Human Heredity, 1970, 20. $30-56$.

NOTE

1. R. S. Wilson and E. B. Harpring. Mental development in infant twins. Unpublished manuscript. 1971.

\section{CURRENT LITERATURE ON VISION}

ANDREASSI, J. L. (New York University, Bronx, N.Y. 10453), MAYZNER, M. S., DAVIDOVICS, S., \& BEYDA, D. R. Visual evoked potentials at, above, and below two-flash thresholds. Psychonomic Science, 1971, 22, 185-187.

BUTCHARD, N. (University of Manitoba, Winnipeg, Manitoba, Canada), \& PRESSEY, A. W. The effects of closing lines on the two forms of the Müller-Lyer illusion. Psychonomic Science, 1971, 23, 257-258.

CONGREVE, G. R. S. (Addiction Research Foundation, Toronto, Ontario, Canada). Dimensions of subjective response to short-term sensory deprivation. Psychonomic Science, 1971, 22, 220-221.

DYER, F. N. (U.S. Army Medical Research Laboratory, Fort Knox, Ky. 40121). A comparison of chromatic and achromatic versions of the Stroop color-word test. Psychonomic Science, 1971, 22, 235-237.

HOWARD, R. B. (Colgate University, Hamilton, N.Y. 13346), \& EVANS, $G$. Some evidence for the size-distortion explanations of illusions. Psychonomic Science, 1971, 23, 129-131.

KAESS, D. W. (Washington State University, Pullman, Wash. 99163). Analytic and intuitive perceivers in the form constancy task. Psychonomic Science, 1971, 23, 179-180.

LONG, N. R. (University of Queensland, St. Lucia, Brisbane, Queensland 4067, Australia). The effect of visual masking on the critical duration of form. Psychonomic Science, 1971, 22, 193-194.

MATTHEWS, M. L. (University of Guelph, Guelph, Ontario, Canada), \& HENDERSON, L. Facilitation of foveal letter recognition by metacontrast. Psychonomic Science, 1971, 23, 153-155.

MOTTRAM, J. (Macquarie University, North Ryde, New South Wales 2113, Australia), \& SINGER, G. Judgments of body and object verticality in the presence of discordant visual information. Psychonomic Science, 1971, 22, 365-367.

SJOSTROM, K. P. (University of Georgia, Athens, Ga. 30601), \&
POLLACK, R. H. The effect of simulated receptor aging on two types of visual illusions. Psychonomic Science, 1971, 23, 147-148.

STERRITT, G. M. (McClelland Learning Institute, Bradford School, Pueblo, Colo. 81001), MARTIN, V., \& RUDNICK, M. Auditory-visual and temporal-spatial integration as determinants of test difficulty. Psychonomic Science, 1971, 23, 289-291.

WINTERS, J. J., JR. (E. R. Johnstone Training and Research Center, Bordentown, N.J. 08505), \& SPITZ, H. H. The effects of visual acuity and instructions on two-dimensional size constancy. Psychonomic Science, 1971, 22, 195-196.

WOLFGANG, A. (Department of Applied Psychology, Ontario Institute for Studies in Education, 252 Bloor Street West, Toronto 181, Ontario, Canada). Errors and latency of response as a function of order of presentation of tactile-visual stimuli in concept identification. Psychonomic Science, 1971, 22, 237-238. 